\title{
CNC Takım Tezgahlarında Ayna ve Punta Basıncının Talaşlı İmalat Parametrelerine Etkisinin Yüzey Yanıt Yöntemiyle Değerlendirilmesi
}

\author{
Hüseyin GÜRBÜZ1* ${ }^{*}$, Şehmus BADAY², Fikret SÖNMEZ ${ }^{3}$ \\ ${ }^{1}$ Batman Üniversitesi, Makine Mühendisliği Bölümü, Batman \\ ${ }^{2}$ Batman Üniversitesi, Makine ve İmalat Mühendisliği Bölümü, Batman \\ ${ }^{3}$ Manisa Celal Bayar Üniversitesi, Makine Mühendisliği Bölüm, Manisa \\ (ORCID: 0000-0003-1391-172X) (ORCID: 0000-0003-4208-8779) (ORCID: 0000-0003-1718-892X)
}

\begin{abstract}
$\ddot{O} \mathbf{z}$
$\mathrm{Bu}$ çalışmada silindirik parçaların $\mathrm{CNC}$ torna tezgâhına bağlanmasında kullanılan ayna ve punta bağlama mekanizmalarının sıkma basıncı değişimini incelenmiștir. Bu amaçla, sabit kesme parametrelerinde üç farklı ayna ve punta basıncı ile iş parçası yüzeyinden talaş kaldırılmışıır. Bu işlemin ardından titreşim genliği incelenmiş ve yüzey pürüzlülük değerleri ölçülmüştür. Yapılan ölçümlerin değerlendirilmesinde yüzey yanıt yöntemi kullanılmıştır. Bu istatiksel yöntem ile yüzey pürüzlülüğü değerlendirilmiş, deney setinin en etkin parametresinin ayna basıncı olduğu görülmüştür. Ayrıca model ile deney sonuçlarının tahmin yeteneği araştırılmıştır. Tüm yüzey pürüzlülük değerleri sırası ile sisteme girilmeden tahmin edilmiş ve deneysel sonuçların tahmin sonuçları ile ortalama $\% 94,2$ oranında benzeştiği görülmüş̧ür. Titreşim genliğinin araştırılması için de yüzey yanıt yöntemi ile model oluşturulmuştur. Bununla birlikte titreşim genliği bu yöntem ile çözümlenememiştir.
\end{abstract}

Anahtar kelimeler: Ayna ve Punta Basıncı, Yüzey Pürüzlülük, Titreşim, Yüzey Yanıt Yöntemi, CNC Torna.

\section{Evaluation of the Effect of Chuck and Tailstock Pressure on Machining Parameters in CNC Lathe by Response Surface Method}

\begin{abstract}
In this study, the clamping pressure change of chuck and tailstock clamping mechanisms used to connect cylindrical workpiece to the CNC lathe was investigated. For this purpose, the chip was removed from the workpiece surface with three different chuck and tailstock pressure in constant cutting parameters. After this process, the vibration amplitude was examined and the surface roughness values were measured. Response Surface Method was used to evaluate the measurements. With this statistical method, surface roughness was evaluated and it was found that the most effective parameter of the experimental set was the chuck pressure. In addition, the prediction ability of experimental results was investigated with the model. All surface roughness values were estimated without entering the system, respectively, and it was seen that the experimental results were similar to the estimated results with an average of $94.2 \%$. In the investigation of vibration amplitude, a model was created by the response surface method. However, the vibration amplitude could not be resolved by this method.
\end{abstract}

Keywords: Chuck and Tailstock Pressure, Surface Roughness, Vibration, Response Surface Method, CNC lathe.

\section{Giriş}

Talaşlı imalat işlemi, makine parçalarının üretilmesinde kullanılan temel üretim metotlarından biridir. Talaşlı imalatın yüksek standartlarda gerçekleştirilmesi, iş parçalarının uygun bir ayna ve punta basıncıyla bağlanmasıyla ile mümkün olabilir. Çünkü iş parçasının tezgâha düzgün bağlanması yüzey pürüzlülügünü iyileştirmekte, titreşimleri azaltmakta ve talaşlı imalat verimini arttırmaktadır. Günümüzde geleneksel ve geleneksel olmayan bir imalat yöntemi ile üretilmek istenilen iş parçalarından gereksinim duyulan ihtiyaçların en başında düşük yüzey pürüzlülük değerleri yer almaktadır. Talaş

*Sorumlu yazar: huseyin.gurbuz@batman.edu.tr

Geliş Tarihi: 14.08.2020, Kabul Tarihi: 04.01.2021 
kaldırma işleminin amacı, sadece iş parçalarına şekil vermek değil aynı zamanda geometri, boyut bakımından da belirli bir tolerans ve doğruluk derecesine göre ideal bir yüzey kalitesinde imal etmektir [1-2]. Bir iş parçasının yüzey kalitesinin yüksek olması daha uzun ömürlü çalışmasına katkı sağlayarak iş parçası imalatına ayrılmış olan üretim maliyetlerinin azaltmasına yardımcı olacaktır. Aynı zamanda kaliteli işlenmiş bir yüzey; yorulma ömrünü, korozyon ve aşınma direncini önemli derecede iyileştirecektir. Fakat işleme şartları veya imalat sürecindeki diğer problemlerden kaynaklanan yüzey düzensizlikleri istenmeyen yüzey pürüzlülüklerine sebep olmaktadır. Bu problemlerden biri de titreşim (tırlama) olayıdır. Titreşim olayı, kesici takım iş parçasını işlerken oluşan anlık değişimlerden dolayı oluşur [3-5]. İş parçaları işlenirken istenmeyen yüksek yüzey pürüzlülük değerlerinin ve titreşimlerin giderilmesinin ilk adımı iş parçalarının tezgâha doğru bir şekilde bağlanmasıyla sağlanmaktadır. Bir iş parçasının ideal punta ve ayna basıncında bağlanması, iş parçası işlenirken oluşacak salgıları, esnemeyi ve titreşim olayını azaltarak iş parçalarından istenen ideal yüzey kalitesinin elde edilmesine yardımcı olacaktır.

Literatür çalışması doğrultusunda, geleneksel ve geleneksel olmayan işleme yöntemleriyle işlenmiş olan iş parçalarının yüzey pürüzlülügü, titreşim, kesme kuvvetleri, talaş kaldırma oranı gibi çıkış parametrelerinin değerlendirilmesinde Yüzey Yanıt Yöntemi (YYY) kullanılarak yapılan çalışmalar aşağıda özetlenmiştir [6-17]. Chabbi ve ark. [6] Polyoxymethylene polimer iş parçası malzemesinin sementit karbür uçlar ile tornalanmasında optimum kesme şartlarına göre minimum yüzey pürüzlülüğü değerlerini optimize etmek için YYY kullanmışlardır. Ayrıca işleme parametrelerinin yüzey pürüzlülüğ̈ üzerinde istatiksel olarak anlamlılığı için de ANOVA (Varyans analizi) kullanmışlardır. Yüzey pürüzlülüğ̈̈ üzerinde en önemli parametrenin ilerleme olduğunu daha sonra kesme derinliğinin etkili olduğunu ancak kesme hızının bir etkisinin olmadığını belirtmişlerdir. Yadav [7] çalışmasında AISI 1040 çeliğinin tornalanmasında kesme hızı, ilerleme ve kesme derinliği gibi parametrelere bağlı olarak ortalama yüzey pürüzlülüğü değerlerinin optimizasyonunda, Taguchi tabanlı YYY'li hibrit bir model oluşturmuştur. Oluşturmuş olduğu hibrit modelle elde edilen optimum değerler ile Taguchi metodu ile elde edilen değerleri karşılaştırmıştır. Yazar, geliştirmiş olduğu hibrit modelin daha iyi ortalama yüzey pürüzlülüğü değerleri verdiği sonucuna varmıştır. Selaimia ve ark. [8] X2CrNi18-9 paslanmaz çeliğin düzlem yüzey frezelenmesinde yüzey pürüzlülüğü, kesme kuvvetleri, kesme gücü ve talaş kaldırma oranını YYY ile optimize ederek modellemiş̧lerdir. Çalışmalarında deney tasarımı için L27 full faktöriyel ve kesme parametrelerinin etkilerini belirlemek için ANOVA kullanmışlardır. Yaptıkları çalışma neticesinde yüzey pürüzlülügü üzerinde en etkili parametrenin ilerleme, kesme kuvveti ve gücün üzerinde en etkili parametrenin kesme derinliği, talaş kaldırma oranı üzerinde ise hem ilerleme hem de kesme derinliğinin etkili olduğunu belirtmişlerdir. Mia [9] çalışmasında AISI 1060 çeliğinin frezelenmesinde kesme hızı, ilerleme ve kesme şartlarına bağlı olarak yüzey pürüzlülüğü ve kesme kuvvetleri değerlerini YYY ile optimize etmiştir. Deney tasarımında L27 full faktöriyel tasarımı ve giriş parametrelerin etkilerini incelmek için ANOVA kullanmıştır. Deney sonuçları kriyojenik soğutmanın kuru ve geleneksel soğutma yöntemlerine göre daha iyi sonuçlar verdiğini göstermiştir. Mia [10] bir diğer çalışmasında AISI 4140 çeliğinin frezelenmesinde YYY ve Taguchi yöntemi kullanarak ortalama yüzey pürüzlülüğü değerlerini optimize etmiştir. Yüzey pürüzlülüğü üzerinde kesme hızı, ilerleme ve soğutma akış hızının etkisinin tespit etmek için full faktöriyel tasarımını kullanmıştır. Optimum parametreleri: İlerleme 46 mm/dev, kemse hızı $32 \mathrm{~m} / \mathrm{dak}$ ve akışkanın akış hızı ise $150 \mathrm{~mL} / \mathrm{sa}$. olarak elde etmiştir. Ananthakumar ve ark. [11] Monel 400 süper alaşım malzemesinin geleneksel olmayan plazma ark kesim yöntemi ile işlenmesinde yüzey pürüzlülüğü değerlerini optimize etmek için YYY kullanmışlardır. Deneyler sonucunda meydana gelen yüzey pürüzlülüğü değerlerinin matematiksel olarak ifade edilmesi için Box-Behnken tasarım yaklaşımını kullanmışlardır. Bu doğrultuda ikinci dereceden (kuadratic) matematiksel modeller elde etmişlerdir. Sonuç olarak optimum şartları $2400 \mathrm{~m} /$ dak kesme hızında, 3 bar gaz basıncında, $45 \mathrm{~A}$ ark akımında ve iş parçasından $2 \mathrm{~mm}$ uzaklıkta durma mesafesinde bulmuşlardır. Parida ve Maity [12] Monel 400 süper alaşımının sıcak (hot) tornalanması sonucu oluşan yüzey pürüzlülüğü değerlerini ve takım aşınmasını YYY ile optimize etmişlerdir. Kesme hızı, ilerleme, kesme derinliği ve iş parçası sıcaklığı parametrelerinin etkinliğini araştırmak için de ANOVA analizi yapmışlardır. Sonuç olarak YYY ile elde etmiş oldukları ikinci dereceden denklemlerin deney sonuçlarını tahmin etmede iyi sonuçlar verdiğini belirtmişlerdir. Demir ve ark. [13] AISI 1050 çeliğinin delinmesinde elde edilen tepki kuvvetlerini YYY ile analiz etmişlerdir. Bu doğrultuda matematiksel modellerin elde edilmesinde üç seviyeli ve üç faktörlü Box-Behnken tasarım yöntemini kullanmışlardır. Birinci ve ikinci dereceden olmak üzere iki adet 
matematiksel model oluşturmuşlardır. İşleme parametrelerinin etkinliğini de ANOVA testi yaparak ortaya koymuşlardır. İlerleme miktarının deneyler üzerinde en etkili parametre olduğunu ortaya koymuşlardır. Singh ve ark. [14] AISI 4340 çeliğinin tornalanması sonucu oluşan yüzey pürüzlülüğü değerlerini optimize etmek için YYY'ni tercih etmişlerdir. Ayrıca işleme parametrelerinin etkinliğini araştırmak için ANOVA testi yapmışlardır. Sonuç olarak çalışmalarında optimum yüzey pürüzlülüğü değerlerini $250 \mathrm{~m} /$ dak kesme hızı, $0,20 \mathrm{~mm} / \mathrm{dev}$ ilerleme ve $0,5 \mathrm{~mm}$ kesme derinliğinde elde ettiklerini belirtmişlerdir. Manikanda ve ark. [15] EN31 çeliğinin tornalanmasında elde edilen yüzey pürüzlülüğü değerlerini optimize etmek için YYY uygulamışlardır. Ayrıca yüzey pürüzlülüğü değerleri tahmini için de matematiksel model oluşturmuşlardır. Yazarlar, yüzey pürüzlülüğü üzerinde en etkili parametrenin kesme hızı olduğu sonucuna varmışlardır. Aslan [16] AISI 5140 çeliğinin tornalamasında titreşim, kesme kuvvetleri ve takım aşınması üzerinde işleme parametrelerin etkisini belirlemek için YYY ve ANOVA kullanmıştır. ANOVA sonuçları; ölçülen titreşim $(\%$ 81,3), kesme kuvvetleri $(\%$ 92,5) ve takım aşınması $(\%$ 91,4) değerlerinin güvenilir bir aralıkta olduğunu göstermiştir. Yazar, aynı zamanda YYY ile yaptığı optimizasyonda yüksek başarı oranı (\% 87,5) elde ettiğini ifade etmiştir. Prasad ve Babu [17] tornalama işlemlerinde takım aşınması ve titreşim arasındaki ilişkiyi ANOVA ve YYY ile araştırmışlardır. Numerik ve deneysel sonuçlara bağlı olarak yapmış oldukları matematiksel modeller ile deney sonuçlarını sırasıyla 98,6 ve 97,8 yüksek $\mathrm{R}^{2}$ değerleri elde etmişlerdir. YYY ile tahmin edilen sonuçlar ile deney sonuçları yüksek oranda tutarlı olduğunu ifade etmişlerdir.

Literatür incelenmesi sonucunda, çeşitli malzemelerin geleneksel ve geleneksel olmayan işleme sonucu meydana gelen yüzey pürüzlülüğ̈̈, titreşim kesme kuvvetleri, talaş kaldırma oranı gibi çıkış parametrelerinin üzerinde işleme parametrelerinin etkilerini belirlemek için analizlere ve deney tasarım metotlarına dayanan çeşitli deneysel ve istatistiksel çalışmalar yapılmıştır [6-17]. Fakat CNC tornalama işleminde ayna ve punta basıncının titreşim ve yüzey pürüzlülügü üzerindeki etkisini belirlemek için YYY ile optimizasyon yapan her hangi bir deneysel ve istatiksel çalışma yapılmadığ 1 tespit edilmiştir. Yapılan bu deneysel ve istatiksel çalışmayla, CNC torna tezgâhlarında iş parçası malzemesinin uygun bir şeklide punta ve ayna basınçta bağlanmasını sağlamak ve bu sayede iş parçasında oluşabilecek yüksek değerlerdeki titreşim ve yüzey pürüzlülük değerleri gibi olumsuz etkilerin giderilmesi amaçlanmiştır.

\section{Materyal ve Metot}

Bu deneysel çalışmada, makine parçalarının üretiminde sıklıkla kullanılan AISI 304 paslanmaz çelik malzeme kullanılmıştır. Bu malzeme içerisinde bulundurduğu yüksek miktarda krom oranından dolayı iyi bir korozyon direncine sahiptir. Ayrıca bu malzeme kaynak yapılabilirliği ile öne çıkmaktadır. Malzemeye ait kimyasal bileşim Tablo 1'de görülmektedir.

Tablo 1. AISI 304 malzemeye ait kimyasal bileşimi

\begin{tabular}{|c|c|c|c|c|c|}
\hline$\% \mathrm{Cr}$ & $\% \mathrm{Ni}$ & $\% \mathrm{Mn}$ & $\% \mathrm{Si}$ & $\% \mathrm{C}$ & $\% \mathrm{Fe}$ \\
\hline $17,50-19,50$ & $8,00-10,50$ & $1,45-2,0$ & $0,39-1,00$ & $0,024-0,070$ & Kalan \\
\hline
\end{tabular}

İş parçalarının yüzeyindeki dış olumsuzlukları gidermek için $36 \mathrm{~mm}$ çapta temin edilen AISI 304 iş parçaları Şekil 1'de görüldüğü gibi $35 \mathrm{~mm}$ çapa düşürülmüştür. Daha sonra her bir iş parçası eşit deney şartlarında işlenebilmesi için $300 \mathrm{~mm}$ boy ölçülerinde hazırlanmıştır. İş parçaları ilk olarak alın yüzeyinden tornalanmış sonrasında ise punta delikleri delinerek boyuna tornalama işlemi için hazırlanmıştır.

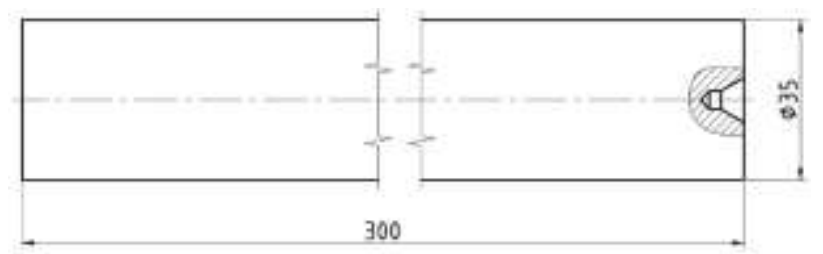

Şekil 1. AISI 304 İş parçası 
CNC torna tezgâhında, kesme parametrelerine bağlı olarak yapılacak işleme deneylerinde kullanılacak olan kesici uç ve takım tutucusu Şekil 2'de verilmiştir. Kesici uç seçiminde çift taraflı, pozitif talaş açısına sahip WNMG 080408-OMM form yapısına sahip PVD kaplamalı kesici uç seçilmiştir. Bu kesici uç, orta kaba talaş kaldırmaya uygun başta karbon çelikleri olmak üzere paslanmaz çelikler içinde kullanılan çok amaçlı bir kesicidir. Seçilen bu kesici uç, geometrik yapısına uygun olan PWLNR 2525M08 takım tutucu ile birlikte kullanılmıştır.

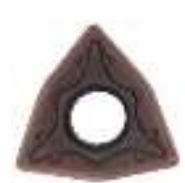

(a)

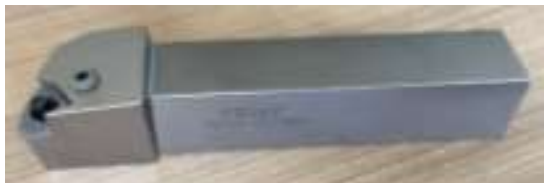

(b)

Şekil 2. (a) WNMG kesici uç, (b) PWLNR 2525M08 takım tutucu

İşleme deneyleri TAKISAWA EX-310 marka CNC torna tezgâhında gerçekleştirilmiştir. İşleme deneylerinde kullanılan işleme parametrelerinin seçiminde kesici uç katalog değerleri ve ISO 3685 standartları göz önüne alınarak deney seti oluşturulmuştur. Deneylerde kesme hızı 250 m/dak, ilerleme $2 \mathrm{~mm} / \mathrm{dev}$ ve kesme derinliği $2 \mathrm{~mm}$ olarak belirlenmiştir. Gerçekleştirilen tüm işleme deneylerinde bu işleme parametreleri sabit tutulmuştur. Yüzey pürüzlülüğü ve titreşim üzerinde etkisi olduğu düşünülen ayna basıncı ve punta basıncı ise değişken parametreler olarak belirlenmiştir. Deneylerde kullanılan parametreler ve bu parametrelerin sayısal değerleri Şekil 3'te görülmektedir.

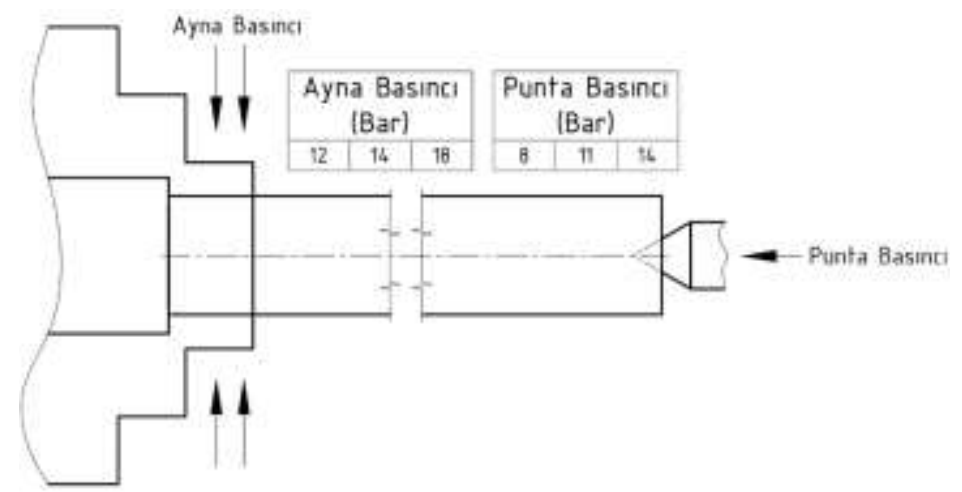

Şekil 3. Deneylerde kullanılan parametreler

İşleme deneyleri esnasında ölçülen titreşim değerleri ve işleme deneyleri sonucunda iş parçasının yüzeyinden ölçülen yüzey pürüzlülük ölçümlerini Şekil 4’te uygulanan sistematik yaklaşıma göre elde edilmiştir. İş parçası için değişken parametreler olan ayna ve punta basınç değerleri tezgâh üzerinde ayarlandıktan sonra talaşlı imalat işlemleri yapılmıştır. İşleme deneyleri esnasında takım tutucuya bağlanan X,Y ve Z koordinatlarında ölçüm yapabilen NI-9230 ivmeölçer ölçüm cihazı ile veriler bilgisayar ortamına aktarılmıştır. İşleme deneyleri sonucunda iş parçasının yüzeyinde oluşan yüzey pürüzlülügü taşınabilir TR 200 ölçüm cihazı kullanılarak ölçülmüştür. Yüzey pürüzlülük değerlerinin tespitinde iş parçası yüzeyinden beş ayrı ölçüm bölgesi belirlenmiştir. Her ölçüm bölgesinden $5 \mathrm{~mm}$ ölçme boyu ile ortalama yüzey pürüzlülüğü değerleri tespit edilmiştir. Tespit edilen 5 yüzey pürüzlülüğü değerinin aritmetik ortalaması alınarak iş parçasına ait ortalama yüzey pürüzlülüğü belirlenmiştir.

AISI 304 çeliğinin tornalanması sonucunda elde edilen ortalama yüzey pürüzlülüğü ve titreşim genliği değerleri Tablo 2'de verilmiştir. 


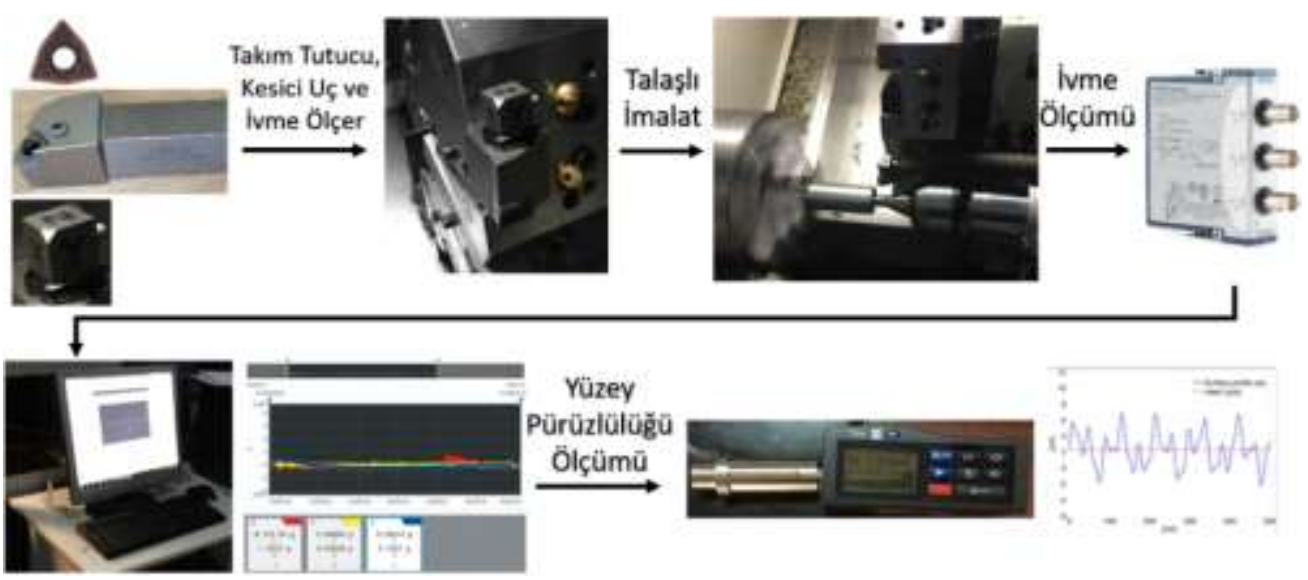

Şekil 4. Deneylerin uygulama sistematiği

Tablo 2. Deney Sonuçları

\begin{tabular}{cccc}
\hline Ayna Basıncı (Bar) & Punta Basıncı (Bar) & Yüzey Pürüzlülüğ̈̆, Ra $(\boldsymbol{\mu m})$ & Titreşim Genliği (g) \\
\hline 14 & 11 & 1,22433 & 3,66 \\
14 & 14 & 1,199 & 3,85 \\
14 & 17 & 1,31667 & 2,72 \\
16 & 11 & 1,365 & 3,48 \\
16 & 14 & 1,48333 & 3,75 \\
16 & 17 & 1,37233 & 5,69 \\
18 & 11 & 1,20067 & 2,16 \\
18 & 14 & 1,274 & 2,37 \\
18 & 17 & 1,23667 & 1,6 \\
\hline
\end{tabular}

\section{Bulgular ve Tartışma}

\subsection{Deney Sonuçlarının YYY ile Değerlendirilmesi}

İşleme esnasında elde edilen titreşim genliği ve işleme sonucunda elde edilen yüzey pürüzlülüğü değerlerinin değerlendirilmesinde YYY kullanılmıştır. YYY deney sisteminde yanıtın, farklı parametrelere ait değerlerin değişimini optimize etmek için kullanılan bir yöntemdir [6,7,9]. Bu yöntem, sistemi modellerken matematiksel formüllerden yararlanılır. Tablo 3'te görüldügü gibi kullanılan matematiksel denklemler temel olarak lineer ve ikinci derece (kuadratik) denklemlerden oluşur.

Tablo 3. YYY ile kullanılan denklemler

\begin{tabular}{ccc}
\hline Lineer & İkinci derece-Lineer (kuadratik) & İkinci derece-Nonlineer \\
\hline$Y=\beta_{0}+\beta_{1} X_{1}+\beta_{2} X_{2}+\beta_{3} X_{3}$ & $Y=\beta_{0}+\beta_{1} X_{1}+\beta_{2} X_{2}+\beta_{3} X_{1} X_{2}$ & $Y=\beta_{0}+\beta_{1} X_{1}+\beta_{2} X_{2}+\beta_{11} X_{1}^{2}+\beta_{22} X_{2}^{2}+\beta_{12} X_{1} X_{2}$ \\
\hline
\end{tabular}

İşleme deneyleri sonucunda elde edilen deneysel sonuçlar YYY yöntemi kullanılarak değerlendirilmiştir. Yapılan değerlendirmede yüzey pürüzlülük değerleri ve titreşim genliği değerleri için farklı YYY modelleri oluşturulmuştur. YYY modellerinde Tablo 4'te görülen parametreler giriş parametresi olarak belirlenmiştir.

Tablo 4. Kullanılan parametreler ve seviyeler

\begin{tabular}{lllccc}
\hline Sembol & Parametre & Birim & Seviye -1 & Seviye 0 & Seviye 1 \\
\hline$a$ & Ayna Basinc1 & Bar & 14 & 16 & 18 \\
$p$ & Punta Basinc1 & Bar & 11 & 14 & 17 \\
\hline
\end{tabular}

Oluşturulan modelde Merkezi Komposit (Central Composite) tasarım kullanılmıştır. Tablo 4 'te verilen değerler kullanılarak 14 deneyden oluşan bir veri seti oluşturulmuştur. Bu veri setinde YYY de kilit rol alan alfa değeri 1 alınmıştır (Face Centered). Oluşturulan model tarafından üretilen deney seti Tablo 5'te görülmektedir. 
Tablo 5. Veri seti

\begin{tabular}{cccccc}
\hline $\begin{array}{c}\text { Deney } \\
\text { No }\end{array}$ & Blok No & $\begin{array}{c}\text { Ayna } \\
\text { Basıncı } \\
\text { Kodlanmıs }\end{array}$ & $\begin{array}{c}\text { Ayna Basıncı } \\
\text { (Bar) }\end{array}$ & $\begin{array}{c}\text { Punta Basıncı } \\
\text { Kodlanmış }\end{array}$ & $\begin{array}{c}\text { Punta Basincı } \\
\text { (Bar) }\end{array}$ \\
\hline 1 & 1 & -1 & 14 & -1 & 11 \\
2 & 1 & 1 & 18 & -1 & 11 \\
3 & 1 & -1 & 14 & 1 & 17 \\
4 & 1 & 1 & 18 & 1 & 17 \\
5 & 1 & 0 & 16 & 0 & 14 \\
6 & 1 & 0 & 16 & 0 & 14 \\
7 & 1 & 0 & 16 & 0 & 14 \\
8 & 2 & -1 & 14 & 0 & 14 \\
9 & 2 & 1 & 18 & 0 & 17 \\
10 & 2 & 0 & 16 & -1 & 14 \\
11 & 2 & 0 & 16 & 1 & 14 \\
12 & 2 & 0 & 16 & 0 & 14 \\
13 & 2 & 0 & 16 & 0 & 0 \\
14 & 2 & 0 & 16 & 0 & \\
\hline
\end{tabular}

\subsection{Yüzey Pürüzlülüğünün Analizi}

Yüzey pürüzlülüğü değerinin değerlendirilmesi için oluşturulan modelde $\mathrm{R}^{2}$ değeri $\% 96,8$ değerine ulaşmıştır. Bu yüksek $\mathrm{R}^{2}$ değeri modelin uygun olabileceğini göstermektedir. Modelin ANOVA analizi (Tablo 6) ile modelde kullanılan değişkenlerin etkinlik düzeyleri tespit edilebilir.

Tablo 6. Yüzey Pürüzlülüğü için oluşturulan ANOVA tablosu

\begin{tabular}{lccccc}
\hline Kaynak & DF & Adj SS & Adj MS & F-Değeri & P-Değeri \\
\hline Model & 6 & 0,167329 & 0,027888 & 35,33 & 0,000 \\
\hline Bloklar & 1 & 0,004801 & 0,004801 & 6,08 & 0,043 \\
Birinci Derece (Lineer) Model & 2 & 0,021089 & 0,010544 & 13,36 & 0,004 \\
Ayna Basıncı (Bar) & 1 & 0,006845 & 0,006845 & 8,67 & 0,022 \\
Punta Basıncı (Bar) & 1 & 0,014244 & 0,014244 & 18,04 & 0,004 \\
Kare & 2 & 0,105070 & 0,052535 & 66,55 & 0,000 \\
Ayna Basıncı (Bar) x Ayna Basıncı (Bar) & 1 & 0,051941 & 0,051941 & 65,79 & 0,000 \\
Punta Basıncı (Bar) x Punta Basıncı (Bar) & 1 & 0,017382 & 0,017382 & 22,02 & 0,002 \\
2-Way Interaction & 1 & 0,004994 & 0,004994 & 6,33 & 0,040 \\
Ayna Basıncı (Bar)*Punta Basıncı (Bar) & 1 & 0,004994 & 0,004994 & 6,33 & 0,040 \\
Hata & 7 & 0,005526 & 0,000789 & & \\
Uyum Eksikliği & 3 & 0,005526 & 0,001842 & & \\
Saf Hata & 4 & 0,000000 & 0,000000 & & \\
Toplam & 13 & 0,172855 & & & \\
\hline
\end{tabular}

ANOVA analizi sonucunda elde edilen parametre verilerinin değerlendirildiğinde Şekil 5'te görülen grafikler elde edilmektedir. Yüzey Pürüzlülüğ̈̈nün YYY ile modellenmesi birinci ve ikinci derece denklemler kullanılmıştır. Problemin çözümünde bu denklemlerin çözüm oluşturamadığı bölümler hata oranlarını oluşturmaktadır. ANOVA analizindeki veriler incelendiğinde ve parametreler toplam parametre toplamlarına bölündüğünde hata miktarının yaklaşı \%3 olduğu anlaşılmaktadır. Şekil 5 'te sadece birinci ve ikinci derece denklemlerde kullanılan parametrelerin etkinliği ortaya çıkarılmıştır. Böylelikle en etkin parametrenin analizi daha kolay yapılabilir.

Şekil 5'te verilen grafikler incelendiğinde hem birinci derece ifadelerde hem de ikinci derece ifadelerde ayna basıncı parametresinin etkinliği daha fazla olmaktadır. Birinci derece ifadelerde ayna basınc1 \%67,5 etkinliğe sahiptir. Bununla birlikte punta basıncının etkinliği \%32,5 olarak şekillenmektedir. İkinci derece ifadeler incelendiğinde ise birinci derece ifadelere benzer şekilde, ayna basıncının kendisi ile çarpımı yani ayna basınıcının karesi ana etkiyi oluşturmaktadır. \%70'e yakın etkiyi tek başına oluşturan bu parametreden sonra \%23,4 etkinlik ile punta basınıcının karesi gelmektedir. Bu iki faktörün birbiri ile etkileşimi (ayna basıncı x punta basıncı) \%6,7 etki oluşturmaktadır. Parametrelerin değişiminin yüzey pürüzlülüğü üzerindeki etkisini analizi için iki parametre birlikte 
değerlendirilmiştir (Şekil 6.). Her iki parametre de farklı eksenlerde oluşturularak etkisinin daha iyi anlaşlabilmesi hedeflenmiştir.

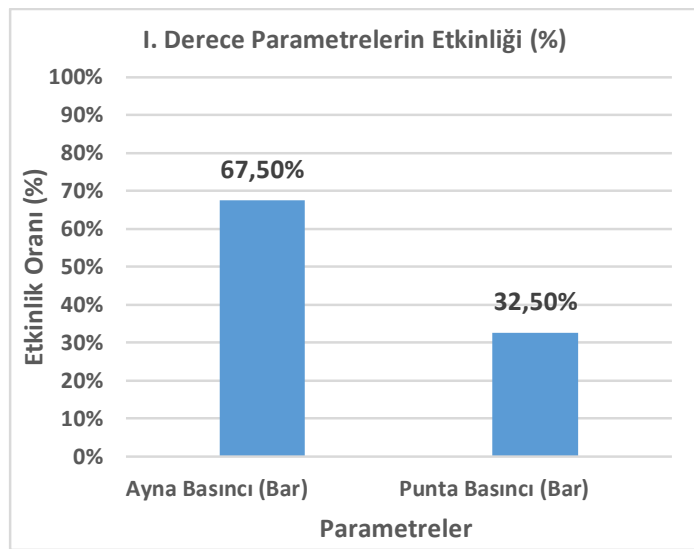

a)

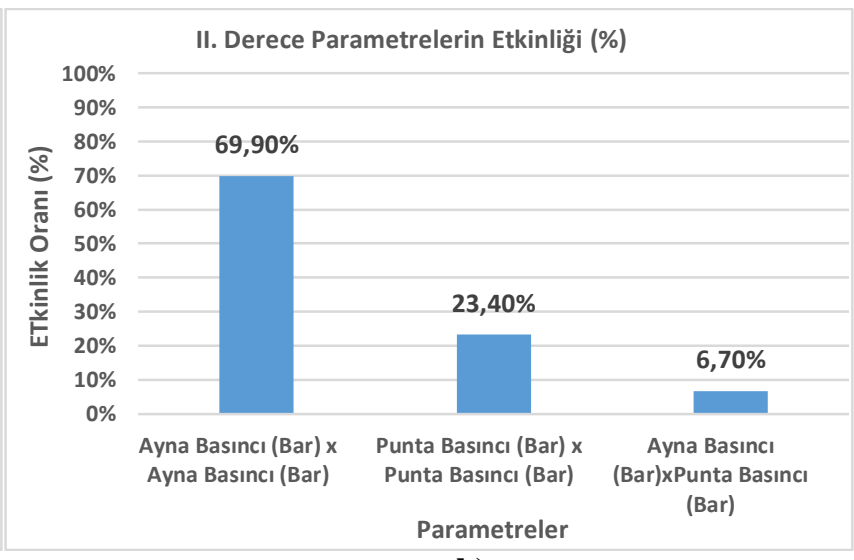

b)

Şekil 5. Parametrelerin etkinliği

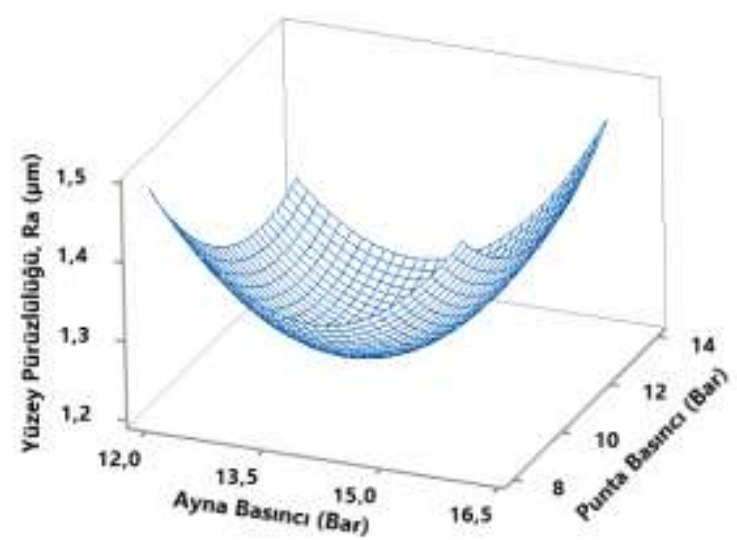

a)

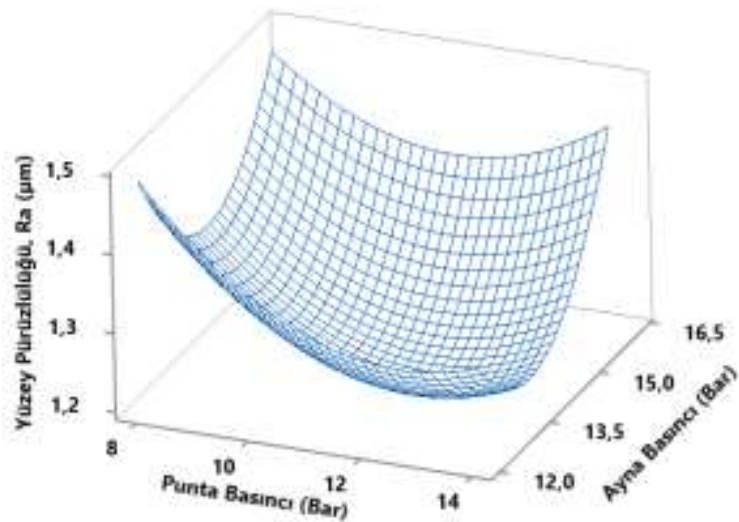

b)

Şekil 6. Parametrelerin Değişiminin Etkisi

Genel olarak yüzey pürüzlülügü değerlerlerin düşük olması makine parçalarında tercih edilen bir durumdur. Şekil 6a'da görülen grafikte artan ayna basıncının önce yüzey pürüzlülügün̈e iyileşme sağladığı sonrasında ise yüzey pürüzlülügünde bozulma gözlemlenmektedir. Punta basıncı ise belirgin bir değişim oluşturmamaktadır. Aynı verileri içeren Şekil 6.b incelendiğinde ise punta basıncının etkisi daha belirgin oldugu görülmektedir. Genel olarak punta basıncının artışı yüzey pürüzlülügünü iyileştirmektedir. Bu etki punta basıncının en yüksek olduğu değerde belli bir miktar bozulma olsa da genel olarak iyileşmektedir. Bununla birlikte yüksek ayna basıncı ile birlikte uygulanan punta basıncı belirgin etki oluşturmamaktadır fakat punta basıncının ortalama değerlerinde en iyi yüzey pürüzlülügünü oluşturmaktadır. YYY ile modellenen deneylerin değerlendirilmesinde modelin tahmin yeteneğinin araştırılması büyük önem taşır. Modelin mevcut veriler dışında yeni parametreler kullarak sonuçları tahmin etme yeteneği modelin geçerliliğini göstermektedir. YYY ile oluşturulan bu modelin problemleri çözmede kullandığı formül hesaplatılmıştır. Bu formül Eşitlik 1'de görülmektedir.

Yüzey Pürüzlülüğü, $\operatorname{Ra}(\mu \mathrm{m})=9,902-1,014 a-0,2938 p+0,03450 a^{2}+0,00887 p^{2}+0,00589 a x p$

Ayna Basinc1 $=a$, Punta Basinc1 $=p$

Eşitlik 1, modelde tüm veriler kullanıldığında elde edilen formüldür. Her oluşturulan yeni model yeni bir tahmin formülü (fonksiyon) üretmektedir. Çalışmanın bu kısmında modelin tahmin yeteneneği araştırılmıştır. $\mathrm{Bu}$ amacla oluşturulan modelde yer alan 9 deney verisi birer birer silinerek model eksik veriler ile oluşturulmuştur. Toplamda her verinin çıkarılması ile 9 adet yeni model oluşturulmuş ve 
oluşturulan modellere ait formüller eksik verinin tahmini için kullanılmıştır. Oluşturulan formüller ile oluşturulan grafik Şekil 7'de görülmektedir. Şekil 7'de görülen grafiğin daha iyi anlaşılabilmesi için deney sonuçları ile tahmin sonuçlarının yüzde benzerlik oranları oluşturulmuş ve bu durum Şekil 7'de sunulmuştur.

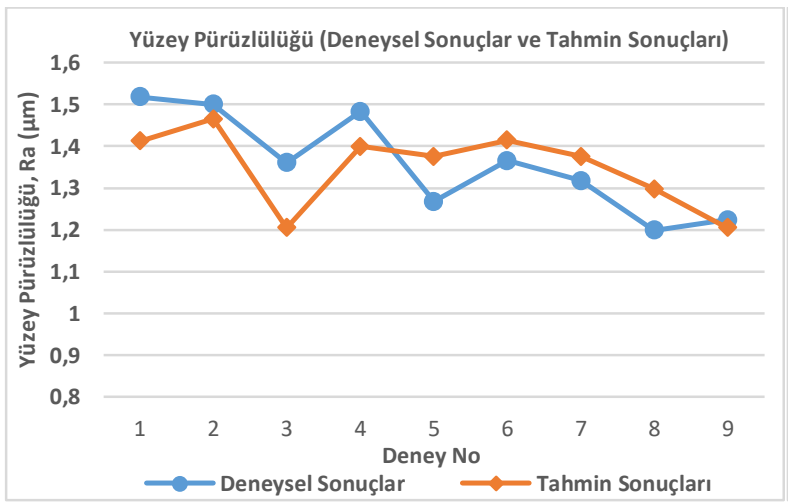

a)

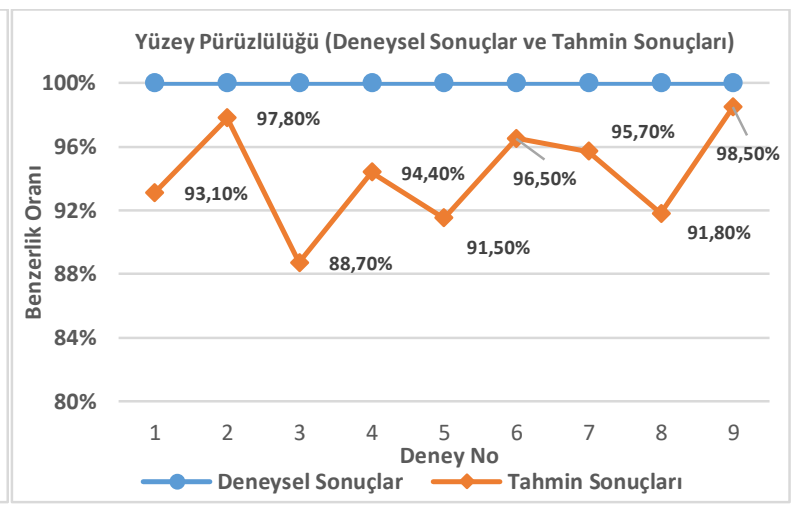

b)

Şekil 7. Modelin Tahmin Yeteneği

Şekil 7(a)'da bulunan grafikte tahmin sonuçlarının büyük oranda deneysel sonuçlarla örtüştügü görülmektedir. Bununla birlikte tahmin sonuçlarının daha iyi anlaşılabilmesi için Şekil 7(b) incelendiğinde deney sonuçlarının neredeyse tamamı $\% 90$ değerinden daha fazla benzerlikle sonuçları tahmin edebilmektedir. Sadece bir sonuç \%88 başarım göstermektedir. Tahmin setinin ortalama başarımı ise \%94.2 olarak şekillenmiştir. Her iki grafikde incelendiğinde YYY bu problemin yüzey pürüzlülüğü değerlerinin çözümlenmesinde kullanılabilecegini göstermektedir.

\subsection{Titreşim Genliğinin Analizi}

Titreşim genliği değerinin değerlendirilmesi için Tablo 7'de görülen ANOVA analizi gerçekleştirilmiştir. YYY ile oluşturulan modelde $\mathrm{R}^{2}$ değeri yüzey pürüzlülüğü değerinden oldukça farklı olarak \%40,7 olmuştur. Bu değer, modelin değerlendirilmesinde yeterli doğruluğu sunmaktan uzaktır. ANOVA analizi sonucunda elde edilen parametre verileri incelendiğinde hata oranlarının kareler toplamı (Adj SS) sütununda en büyük değere sahip olduğu görülmektedir. Bu durumda parametrelerin titreşim genliği değerini hesaplamayacağı görülmektedir. ANOVA analizine göre sistemin hata oranı $\% 59$ olarak şekillenmektedir. YYY ile yapılan hem yüzey pürüzlülüğü hem de titreşim modellemelerinde farklı sonuçlar elde edilmiştir. Yüzey pürüzlülüğünde oldukça iyi değerlendirmeler yapabilen YYY modeli, titreşim genliğinin hesaplanmasında başarısız olmaktadır. Bu durum titreşim genliğinin çok daha fazla parametreden etkilenmesi ile açıklanabilir. Mevcut parametreler kullanılarak sistemin çözüm üretmesi mümkün değildir.

Tablo 7. Titreşim Genliği için oluşturulan ANOVA tablosu

\begin{tabular}{llllll}
\hline Kaynak & DF & Adj SS & Adj MS & F-Değeri & P-Değeri \\
\hline Model & 6 & 5,9015 & 0,98359 & 0,80 & 0,598 \\
Bloklar & 1 & 0,5448 & 0,54476 & 0,44 & 0,526 \\
Birinci Derece (Lineer) Model & 2 & 0,7824 & 0,39121 & 0,32 & 0,737 \\
Ayna Basıncı (Bar) & 1 & 0,5581 & 0,55815 & 0,46 & 0,521 \\
Punta Basıncı (Bar) & 1 & 0,2243 & 0,22427 & 0,18 & 0,682 \\
Kare & 2 & 4,2879 & 2,14393 & 1,75 & 0,242 \\
Ayna Basıncı (Bar) x Ayna Basıncı (Bar) & 1 & 3,2106 & 3,21061 & 2,62 & 0,150 \\
Punta Basıncı (Bar) x Punta Basıncı (Bar) & 1 & 2,6193 & 2,61927 & 2,14 & 0,187 \\
2-Way Interaction & 1 & 0,1225 & 0,12250 & 0,10 & 0,761 \\
Ayna Basıncı (Bar)*Punta Basıncı (Bar) & 1 & 0,1225 & 0,12250 & 0,10 & 0,761 \\
Hata & 7 & 8,5818 & 1,22598 & & \\
Uyum Eksikliği & 3 & 8,5818 & 2,86061 & & \\
Saf Hata & 4 & 0,0000 & 0,00000 & & \\
Toplam & 13 & 14,4833 & & & \\
\hline
\end{tabular}




\section{Sonuç ve Öneriler}

Yapılan bu çalışmada AISI 304 paslanmaz çelik iş parçalarının sabit kesme parametrelerinde farklı ayna ve punta basıncında tornalanması sonucu oluşan titreşim ve yüzey pürüzlülüğü değerlerinin değişimi araştırılmıştır. İş parçasının bağlanmasında kullanılan ayna ve punta basınçlarının etkileri değerlendirilmiş ve YYY ile yüzey pürüzlülüğü ve titreşim genliği değerleri analiz edilmiştir.

a) YYY, yüzey pürüzlülügü işlemini yüksek $R^{2}(96,8 \%)$ değeri ile değerlendirebilmektedir.

b) Yüzey pürüzlülüğ̈ değerlerinin tahmin edilmesinde YYY etkin olarak kullanılabilmektedir. Ortalama tahmin yeteneği \%94,2 olarak şekillenmiştir.

c) Yüzey pürüzlülüğü değerlerinin modellenmesinde kullanılan parametrelerin birinci ve ikinci derece terimlerinde de en etkin faktör ayna basıncı faktörüdür. Bu faktör \%70'e yakın oranda sonuçlar1 etkilemektedir.

d) Ayna basıncındaki artış yüzey pürüzlülügünü iyileştirmekte ancak bu parametrenin artışı yüzeyi bozmaya başlamaktadır. Benzer şekilde punta basıncındaki artışta yüzey pürüzlülügüunü iyileştirmekte ancak en yüksek punta değeri yüzey pürüzlülüğünü belirli bir miktar geriye çekmektedir.

e) Yüzey pürüzlülüğünü başarıyla değerlendiren bu model, titreşim genliğinin değerlendirilmesinde ise oldukça kötü sonuçlar üretmektedir. YYY ile oluşturulan titreşim genliği modeli yaklaşı $\% 40 \mathrm{R}^{2}$ değeri üretmektedir. $\mathrm{Bu}$ durum mevcut veri setinin ve parametrelerin titreşimi çözümleyemediğini ortaya koymaktadır.

\section{Teşekkür}

2209/B sanayi odaklı lisans bitirme tezi destekleme programı kapsamında bizleri finansman noktasında destekleyen TÜBİTAK'a, deneyler sırasında her türlü desteği veren Yavuzlar Kardeşler Makine'ya ve ayrıca ölçüm cihazları için de Batman Üniversitesi Makine Mühendisliği' ne teşekkür ederiz.

\section{Yazarların Katkısı}

Bu makaledeki deneysel çalışma kısmı ve deneysel sonuçların yorumlanması Hüseyin GÜRBÜZ ve Şehmus BADAY tarafindan, deneysel sonuçların YYY ile değerlendirilmesi ise Fikret SÖNMEZ tarafindan yapılmıştır.

\section{Çıkar Çatışması Beyanı}

Yazarlar arasında herhangi bir çıkar çatışması bulunmamaktadır.

\section{Araştırma ve Yayın Etiği Beyanı}

Yapılan çalışmada araştırma ve yayın etiğine uyulmuştur.

\section{Kaynaklar}

[1] Gürbüz H., Baday Ş. 2019. CNC torna tezgâhlarında ayna ve punta basıncının yüzey pürüzlülüğü ve titreşim üzerine etkisinin Taguchi metodu ile optimizasyonu. Bilecik Şeyh Edebali Üniversitesi Fen Bilimleri Dergisi, 6 (2): 119-134.

[2] Nas E., Samtaş G., Demir H. 2012. CNC Frezelemede yüzey pürüzlülügüne etki eden parametrelerin matematiksel olarak modellenmesi. Pamukkale Üniversitesi Mühendislik Bilimleri Dergisi, 18 (1): 47-59.

[3] Venkata Rao K., Murthy B.S.N., Mohan Rao N. 2014. Prediction of cutting tool wear, surface roughness and vibration of work piece in boring of AISI 316 steel with artificial neural network. Measurement, 51: 63-70.

[4] Zhang S.J., To S., Zhang G.Q., Zhu Z.W. 2015. A review of machine-tool vibration and its influence upon surface generation in ultra-precision machining. International Journal of Machine Tools \& Manufacture, 91: 34-42. 
[5] Neşeli S., Yaldız S. 2007. Tornalamada yaklaşma açısı ve talaş açısına bağlı tırlama titreşimlerinin yüzey pürüzlülüğüne etkileri. Politeknik Dergisi, 10 (4): 383-389.

[6] Chabbi A., Yallese M.A., Meddour I., Nouioua M., Mabrouki T., Girardin F. 2017. Predictive modeling and multi-response optimization of technological parameters in turning of Polyoxymethylene polymer (POM C) using RSM and desirability function. Measurement, 95: 99115.

[7] Yadav R.N. 2017. A hybrid approach of Taguchi-Response surface methodology for modeling and optimization of duplex turning process. Measurement, 100: 131-138.

[8] Selaimia A.A., Yallese M.A., Bensouilah H., Meddour I., Khattabi R., Mabrouki T. 2017. Modeling and optimization in dry face milling of X2CrNi18-9 austenitic stainless steel using RMS and desirability approach. Measurement, 107: 53-67.

[9] Mia M. 2017. Multi-response optimization of end milling parameters under through-tool cryogenic cooling condition. Measurement, 111: 134-145.

[10] Mia M. 2018. Mathematical modeling and optimization of MQL assisted end milling characteristics based on RSM and Taguchi method. Measurement, 121: 249-260.

[11] Ananthakumar K., Rajamani D., Balasubramanian E., Davim J.P. 2019. Measurement and optimization of multi-response characteristics in plasma arc cutting of Monel $400^{\mathrm{TM}}$ using RSM and TOPSIS. Measurement, 135: 725-737.

[12] Parida A.K., Maity K. 2019. Modeling of machining parameters affecting flank wear and surface roughness in hot turning of Monel-400 using response surface methodology (RSM). Measurement, 137: 375-381.

[13] Demir Z., Baday Ş., Sönmez F. 2020. AISI 1050 Çelik malzemenin delinmesinde tepki kuvvetini etkileyen parametrelerin yüzey yanıt yöntemi ile analizi. Fırat Üniversitesi Mühendislik Bilimleri Dergisi, 32 (1): 75-85.

[14] Singh B.K., Roy H, Mondal B, Roy S.S., Mandal N. 2019. Measurement of chip morphology and multi criteria optimization of turning parameters for machining of AISI 4340 steel using Y-ZTA cutting insert. Measurement, 142: 181-194.

[15] Manikanda P.K., Pradheep T., Suresh S. 2017. Application of Taguchi and Response Surface Methodology (RSM) in steel turning process to improve surface roughness and material removal rate. Materials Today: Proceedings, 5: 24622-24631.

[16] Aslan A. 2020. Optimization and analysis of process parameters for flank wear, cutting forces and vibration in turning of AISI 5140: A comprehensive study. Measurement, 163: 107959.

[17] Prasad B.S., Babu M.P. 2017. Correlation between vibration amplitude and tool wear in turning: Numerical and experimental analysis. Engineering Science and Technology, an International Journal, 20 (1): 197-211. 